\title{
MÃE E FILHO NO CÁRCERE: UMA REVISÃO SISTEMÁTICA
}

\section{MOTHER AND SON IN THE CARCERE: A SYSTEMATIC REVIEW}

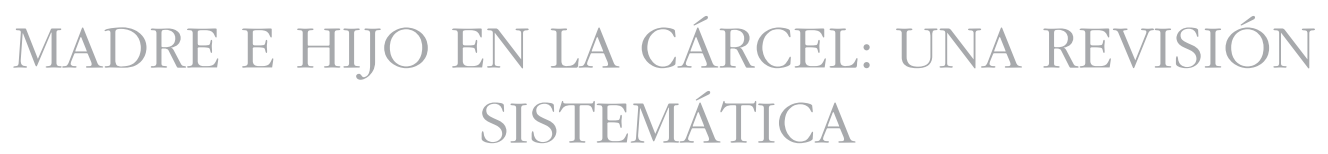

Denise Santana Silva dos Santos ${ }^{1}$ Tânia Christiane Ferreira Bispo ${ }^{2}$

Como citar este artigo: Santos DSS, Bispo TCF. Mãe e filho no cárcere: uma revisão sistemática. Rev baiana enferm. 2018;32:e22130.

Objetivo: analisar a produção científica acerca da relação mãe e filho no contexto de privação de liberdade. Metodologia: trata-se de uma revisão sistemática da literatura, orientada pelos descritores "relação mãe-filho", "prisões", "recém-nascido" e "criança". Foram acessadas seis bases de dados da Biblioteca Virtual de Saúde e selecionados 13 artigos que aderiam à temática e aos critérios de inclusão. Os dados foram analisados e apresentados em categorias. Resultados: após a análise foram delineadas três categorias: vivenciando a maternidade no ambiente hostil da prisão, relação mãe-filho e formação do vínculo no cárcere e sofrimento psíquico da separação do binômio. Conclusão: a produção científica acerca da relação mãe e filho no contexto de privação de liberdade mostra que é necessária maior atenção à mulher que vivencia a maternidade em situação de privação de liberdade, tendo em vista que o ambiente da prisão tem fortes implicações para o estabelecimento da relação mãe-filho e para a formação do vínculo nesse binômio.

Descritores: Relação mãe-filho. Prisões. Recém-nascido. Criança.

Aim: analyze the scientific production about the mother and child relationship in the context of deprivation of liberty. Methodology: this is a systematic review of the literature, guided by the descriptors "mother-child relationship", "prisons", "newborn" and "child". Six databases were accessed from the Virtual Health Library and 13 articles that adhered to the theme and the inclusion criteria were selected. Results: after the analysis, three categories were outlined: experiencing motherhood in the hostile environment of the prison, mother-child relationship and bond formation in jail and psychic suffering of the separation of the binomial. Conclusion: the scientific production on the relationship between mother and child in the context of deprivation of liberty shows that greater attention is needed to the woman who experiences maternity in situations of deprivation of liberty, given that the prison environment has strong implications for the establishment of the mother-child relationship and for the formation of the bond in this binomial.

Descriptors: Mother-child relationship; Prisons; Newborn; Child.

Objetivo: analizar la producción científica acerca de la relación madre e bijo en el contexto de privación de la libertad. Metodologia: se trata de una revisión sistemática de la literatura, orientada por los descriptores "relación madre-hijo", "prisiones", "recién nacido" y "niño". Se accedieron seis bases de datos de la Biblioteca Virtual de Salud y se seleccionaron 13 artículos relacionados a la temática y a los criterios de inclusión. Los datos fueron analizados y presentados por categorías. Resultados: después del análisis se delinearon tres categorías: experimentando la

Enfermeira. Mestre em Enfermagem. Especialista em Neonatologia. Docente na Universidade do Estado da Bahia. Salvador, Bahia, Brasil. denisenegal@hotmail.com Enfermeira. Pós-doutora em Saúde Coletiva. Docente na Universidade do Estado da Bahia. Salvador, Bahia, Brasil. 
maternidad en el ambiente hostil de la cárcel, relación madre-hijo y la formación del vínculo en la cárcel y el sufrimiento psíquico de la separación del binomio. Conclusión: la producción científica acerca de la relación madre e bijo en el contexto de privación de la libertad muestra la necesidad de darle mayor atención a la mujer que experimenta la maternidad en situación de privación de libertad, considerando que el ambiente carcelario tiene fuertes implicaciones en el estabelecimiento de la relación madre-bijo y en la formación del vínculo de ese binomio.

Descriptores: Relación madre-hijo. Prisiones. Recién nacido. Niños.

\section{Introdução}

A formação dos vínculos afetivos é importante para o desenvolvimento saudável da criança, pois eles influenciarão na formação da sua personalidade e no estabelecimento da confiança que é a base para o relacionamento humano. Quando essa formação de laços estabelece-se no contexto prisional, a relação mãe-filho pode sofrer diversas influências do próprio sistema carcerário.

Estudos realizados no Brasil e em outros países revelam o aumento do número de mulheres cada vez mais jovens em idade fértil que vivenciam a maternidade atrás das grades e estabelecem a relação com seu filho nesse ambiente ${ }^{(1-6)}$.

Pesquisas realizadas em prisão do estado de Nova York demonstraram que, nos últimos 30 anos, a população carcerária feminina dos Estados Unidos aumentou, tornando-se, assim, um grande problema de saúde pública, pois mais de $60 \%$ dessas mulheres presas têm mais de 2 filhos e de 6-10\% engravidam nesse contexto ${ }^{(5,7)}$.

Dados do Sistema Integrado de Informações Penitenciárias (INFOPEN) de 2014, realizado pelo Departamento Penitenciário Nacional, informam que o número de presas subiu, no Brasil, de 5.601 para 37.380 entre os anos de 2000 e 2014, um crescimento dessa população de $567 \%$ em $15 \operatorname{anos}^{(8)}$. Assim, a população carcerária feminina torna-se a quinta maior do mundo, o que traz à tona a situação do binômio mãe-filho no cárcere.

No Brasil, uma das primeiras prisões para mulheres surgiu no Rio de Janeiro em 1942 e foi denominada de "Reformatório Especial", longe das prisões masculinas e sob a administração de freiras $^{(9)}$. No ordenamento jurídico brasileiro, há o preceito legal de inclusão de berçário e a possibilidade de creche/seção para gestante e parturiente dentro das unidades prisionais, conforme preconiza a Lei n. 11.942/09, que alterou a Lei de Execuções Penais de $1984^{(10-11)}$. Portanto, as mulheres que vivenciam a maternidade na prisão são encaminhadas para a Unidade Materno-Infantil (berçário), que é outro pavilhão dentro da própria penitenciária de origem, ficando lá até o sexto mês de vida do seu bebê. Após esse período, ela é separada do seu filho e retorna para o seu pavilhão ${ }^{(1,10)}$. O período de permanência das mães com seus filhos não é consenso nas penitenciárias brasileiras. O prazo mínimo é de seis meses, com enfoque na amamentação, e o máximo é de 1 ano e 6 meses conforme Resolução n. 4, de 15 de julho de 2009, do Conselho Nacional de Política Criminal e Penitenciária (CNPCP) $)^{(12)}$.

Dados da Pesquisa Saúde Materno-Infantil nas prisões do Brasil realizada pela Fundação Oswaldo Cruz em 2012, informam que 2\% do total de mulheres encarceradas estavam grávidas e, no período de um ano, 272 mulheres presas tiveram seu parto no sistema público de saúde. No país, cerca de 400 crianças viviam com suas mães em situação de prisão ${ }^{(3)}$.

As condições insalubres do cárcere no Brasil, evidenciadas pela superlotação das prisões, condições sanitárias e de higiene precária, alimentação inadequada e dificuldades na assistência médica, jurídica e educacional ${ }^{(13)}$ trazem à tona o ambiente a que essas crianças e suas mães estão expostas e as implicações para a saúde de ambas.

Estudo realizado com crianças palestinas evidenciou que a detenção dos pais afeta 
amplamente o bem-estar psicológico das crianças envolvidas, com uma grande variedade de problemas comportamentais, como transtorno de estresse pós-traumático, enurese, pesadelo e ansiedade ${ }^{(14)}$.

Portanto, essas mulheres e seus filhos vivenciam riscos ligados à sua integridade física, exposição às doenças infectocontagiosas e falta de infraestrutura física que deixam essa díade em situação de vulnerabilidade total. Compreende-se, portanto, que a mulher e seu bebê em situação de prisão perdem o direito à liberdade, porém os outros direitos assegurados na Constituição de 1988 devem ser-lhes garantidos.

Diante do exposto, a motivação desta pesquisa surgiu após a realização de um projeto de extensão universitária na penitenciária feminina da cidade de Salvador, Bahia, Brasil. Nesse período, observou-se que existia um número elevado de mulheres que vivenciavam a maternidade na prisão e também a complexidade da relação mãe-filho nesse contexto.

Desse modo, este artigo traz como contribuições para a enfermagem a discussão sobre crianças e mães que estão privadas de liberdade e são atendidos pelo Sistema Único de Saúde (SUS), quer seja no próprio complexo penitenciário, pelo enfermeiro que compõe a equipe de saúde do presídio, quer seja na área de abrangência do Programa Saúde da Família. Esse profissional deverá planejar ações de saúde para esse binômio, levando em consideração os princípios do SUS e as especificidades do cárcere.

Apesar da relevância da temática, pouco se tem estudado sobre isso. Então, a lacuna na literatura identificada nessa área direcionou este estudo para a problemática da maternidade na prisão, que assume especial complexidade pelos efeitos do encarceramento na díade mãe-filho e na formação dos laços afetivos.

Diante desse contexto, a questão norteadora deste artigo é: Quais são as produções científicas acerca da relação mãe-filho no contexto de privação de liberdade?

Com o propósito de contribuir para a reflexão sobre essa problemática, o objetivo deste artigo é analisar a produção científica acerca da relação mãe e filho no contexto de privação de liberdade.

\section{Método}

Estudo de revisão sistemática da literatura, de caráter exploratório e descritivo. A pesquisa de revisão pode propiciar uma apreciação do tema sob um novo enfoque, chegando a novas conclusões, não sendo, assim, a repetição do que já foi dito ou escrito ${ }^{(15)}$. Esse processo permite o aprofundamento do conhecimento sobre a temática, além de apontar lacunas que precisam ser preenchidas por novos estudos.

A busca dos artigos foi realizada em seis bases de dados eletrônicos acessados na Biblioteca Virtual em Saúde (BVS): Medical Literature Analysis and Retrieval System on-line (MEDLINE), Literatura Latino-Americana e do Caribe em Ciências da Saúde (LILACS), Scientific Electronic Library Online (SciELO), National Library of Medicine, EUA (PubMED), Base de dados de Enfermagem (BDENF) e Index Psicologia periódicos técnicos científicos.

Para o levantamento dos estudos foram utilizados os descritores "relação mãe-filho", "prisões", "recém-nascido", "criança", no idioma português, de acordo com os Descritores em Ciências da Saúde (DeCS), e inglês, de acordo com o Medical Subject Headings (MeSH) "mother - child relations", "prisons", "infant, newborn" e "child" adaptados de acordo com a base de dados utilizada.

Três etapas foram seguidas no desenvolvimento do estudo: inicialmente realizou-se a busca pelos descritores "relação mãe-filho" e "prisões", utilizando o operador booleano AND; segundo com os descritores "recém-nascido" e "prisões" conectados pelo operador booleano AND; e por último, "criança" e "prisões". A busca foi realizada no mês de fevereiro de 2017.

Para selecionar a amostra, foram utilizados os seguintes critérios de inclusão: ser artigo original, indexado nas bases de dados selecionadas, nos idiomas português, inglês, francês e espanhol; publicado entre os anos de 2012 e 2016. A escolha desse período atendeu ao critério de 
temporalidade, em que se considerou o recorte de cinco anos, por se tratar de publicações mais atuais.

Os critérios de exclusão foram publicações de tese, dissertação, monografia e artigos que não tinham aderência à temática.

Foi aplicada a técnica de análise de conteúdo temática, constituída de duas etapas: pré-análise e análise ${ }^{(16)}$. Na primeira etapa foi efetuada a leitura flutuante dos textos, que possibilitou a constituição do corpus; seguiu-se com leitura exaustiva desses que, agrupados por similaridade, constituíram as categorias de análise, conforme a compreensão e transversalização do discorrido pelos autores.

\section{Resultados}

A estratégia de busca desta revisão possibilitou a obtenção de 195 estudos, no entanto alguns se repetiam nas bases de dados e cruzamentos dos descritores.

No primeiro cruzamento com os descritores "relação mãe-filho" AND "prisões" na base de dados LILACS foram encontrados 21 artigos. Após utilizar os critérios de inclusão, restaram apenas 3 artigos. Concluída a leitura de título, resumo e texto na íntegra, apenas 2 atendiam ao objetivo da pesquisa. Nas bases de dados SciELO e PUBMED não foram encontrados artigos para esses descritores.

No cruzamento com os descritores "relação mãe-filho" AND "prisões", na base de dados MEDLINE foram encontrados 32 artigos. Após utilizar os critérios de inclusão, apenas 4 permaneceram. Finalizada a leitura de título, resumo e texto na íntegra, restaram 2 artigos que atendiam ao objetivo da pesquisa.

No cruzamento com os descritores "relação mãe-filho" AND "prisões" na base de dados BDENF foram encontrados 12 artigos. Utilizados os critérios de inclusão, restaram 2. Após a leitura de título, resumo e texto na íntegra, apenas 1 atendeu ao objetivo da pesquisa.

No cruzamento com os descritores "relação mãe-filho" AND "prisões" na base de dados Index Psicologia Periódicos técnicos-científicos foram encontrados 6 artigos. Após utilizar os critérios de inclusão, restaram apenas 2. Finalizada a leitura de título, resumo e texto na íntegra, apenas 1 artigo atendia ao objetivo da pesquisa.

No segundo cruzamento com os descritores "recém-nascido" AND "prisões" na base de dados LILACS foram encontrados 18 artigos, mas apenas 2 permaneceram após utilizar-se os critérios de inclusão. Concluída a leitura de título, resumo e texto na íntegra, restou 1 que atendia ao objetivo da pesquisa. Nas bases de dados SciELO, BDENF, PUBMED e Index Psicologia Periódicos Técnicos-científicos não foram encontrados artigos para esses descritores.

No cruzamento com os descritores "recém-nascido" AND "prisões" na base de dados MEDLINE foram encontradas 34 publicações, restando 5 após a utilização dos critérios de inclusão. Depois da leitura de título, resumo e texto na íntegra, restaram 4 artigos que atendiam ao objetivo da pesquisa.

No terceiro cruzamento com os descritores "criança” AND "prisões" na base de dados LILACS foram encontradas 19 publicações, restando apenas 1 artigo após a utilização dos critérios de inclusão e leitura dos títulos e resumos.

Nas bases de dados SciELO, BDENF, PUBMED e Index Psicologia Periódicos Técnicos-científicos não foram encontrados artigos para esses descritores.

No cruzamento com os descritores "criança" AND "prisões" na base de dados MEDLINE foram encontradas 53 publicações, restando apenas 1 artigo após utilização dos critérios de inclusão e leitura de título, resumo e texto na íntegra.

Portanto, dos 195 artigos encontrados, que contemplavam a temática sob a compreensão de diversas disciplinas da área de saúde, após a utilização dos critérios de inclusão e exclusão foram selecionados 22. Estes foram salvos em arquivos doc e $p d f$ e armazenados em pasta própria, sendo identificados conforme o foco de investigação. Em seguida, esse material foi lido na íntegra e analisado criteriosamente. Esse aprofundamento das leituras possibilitou a seleção de 13 artigos, que encontravam compatibilidade com o objetivo da pesquisa (Tabela 1). 
Tabela 1 - Total de artigos encontrados nas bases de dados e selecionados após leitura segundo estratégia de busca. Salvador, Bahia, Brasil - 2017

\begin{tabular}{|c|c|c|c|c|c|c|}
\hline \multirow{2}{*}{$\begin{array}{l}\text { Estratégia } \\
\text { de busca }\end{array}$} & \multirow{2}{*}{ Base de Dados } & \multirow{2}{*}{$\begin{array}{c}\text { Total de } \\
\text { artigos } \\
\text { encontrados }\end{array}$} & \multirow{2}{*}{$\begin{array}{l}\text { Total de artigos } \\
\text { selecionados } \\
\text { após critérios } \\
\text { de inclusão } \\
\text { e exclusão }\end{array}$} & \multicolumn{3}{|c|}{$\begin{array}{c}\text { Total de artigos selecionados } \\
\text { após leitura }\end{array}$} \\
\hline & & & & Título & Resumo & $\mathrm{Na}$ integra \\
\hline \multirow{6}{*}{$\begin{array}{l}\text { Relação } \\
\text { mãe-filho } \\
\text { AND } \\
\text { prisões }\end{array}$} & LILACS & 21 & 3 & 2 & 2 & 2 \\
\hline & SciELO & - & - & - & - & - \\
\hline & MEDLINE & 32 & 4 & 2 & 2 & 2 \\
\hline & BDENF & 12 & 2 & 1 & 1 & 1 \\
\hline & PUBMED & - & - & - & - & - \\
\hline & $\begin{array}{l}\text { Index Psicologia } \\
\text { periódicos } \\
\text { técnicos } \\
\text { científicos }\end{array}$ & 6 & 2 & 1 & 1 & 1 \\
\hline \multirow{6}{*}{$\begin{array}{l}\text { Recém- } \\
\text {-Nascido } \\
\text { AND } \\
\text { prisões }\end{array}$} & LILACS & 18 & 2 & 1 & 1 & 1 \\
\hline & SciELO & - & - & - & - & - \\
\hline & MEDLINE & 34 & 5 & 4 & 4 & 4 \\
\hline & BDENF & - & - & - & - & - \\
\hline & PUBMED & - & - & - & - & - \\
\hline & $\begin{array}{l}\text { Index Psicologia } \\
\text { periódicos } \\
\text { técnicos } \\
\text { científicos }\end{array}$ & - & - & - & - & - \\
\hline \multirow{6}{*}{$\begin{array}{l}\text { Criança } \\
\text { AND } \\
\text { prisões }\end{array}$} & LILACS & 19 & 2 & 1 & 1 & 1 \\
\hline & SciELO & - & - & - & - & - \\
\hline & MEDLINE & 53 & 2 & 1 & 1 & 1 \\
\hline & BDENF & - & - & - & - & - \\
\hline & PUBMED & - & - & - & - & - \\
\hline & $\begin{array}{l}\text { Index Psicologia } \\
\text { periódicos } \\
\text { técnicos } \\
\text { científicos }\end{array}$ & - & - & - & - & - \\
\hline TOTAL & & 195 & 22 & 13 & 13 & 13 \\
\hline
\end{tabular}

Fonte: Elaboração própria.

Nota: Sinal convencional utilizado:

- Dado numérico igual a zero não resultante de arredondamento

Após a leitura, foi construído um quadro com a classificação dos artigos em relação a autor, título, revista, país e ano da publicação (Quadro 1).

Quadro 1 - Total de artigos classificados por autor, título, revista, ano da publicação e país da publicação. Salvador, Bahia Brasil - 2017 (continua)

\begin{tabular}{|c|c|c|c|c|}
\hline No & Autor & Título & Revista & $\begin{array}{c}\text { País } \\
\text { e ano da } \\
\text { publicação }\end{array}$ \\
\hline 1 & $\begin{array}{l}\text { Matão MEL, } \\
\text { Miranda DB, } \\
\text { Malaquias A, } \\
\text { Souza EL }\end{array}$ & $\begin{array}{l}\text { Maternidade atrás das grades: } \\
\text { particularidades do binômio mãe e filho }\end{array}$ & $\begin{array}{l}\text { Rev enferm } \\
\text { Centro-Oeste } \\
\text { Min }\end{array}$ & $\begin{array}{l}\text { Brasil } \\
2016\end{array}$ \\
\hline
\end{tabular}


Quadro 1 - Total de artigos classificados por autor, título, revista, ano da publicação e país da publicação. Salvador, Bahia Brasil - 2017

(conclusão)

\begin{tabular}{|c|c|c|c|c|}
\hline No & Autor & Título & Revista & \begin{tabular}{|c|} 
País \\
e ano da \\
publicação
\end{tabular} \\
\hline 2 & $\begin{array}{l}\text { França AMB, } \\
\text { Silva } \mathrm{JMO}^{(17)}\end{array}$ & $\begin{array}{l}\text { A mulher em situação de prisão } \\
\text { e a vivência da maternidade }\end{array}$ & $\begin{array}{l}\text { Rev enferm } \\
\text { UFPE on line }\end{array}$ & $\begin{array}{l}\text { Brasil } \\
2016\end{array}$ \\
\hline 3 & $\begin{array}{l}\text { Soares IR, Cenci } \\
\mathrm{CMB}^{(9)} \text { Oliveira } \\
\mathrm{LRF}^{(1)}\end{array}$ & $\begin{array}{l}\text { Mães no cárcere: percepção de vínculos } \\
\text { com os filhos }\end{array}$ & $\begin{array}{l}\text { Estud Pesqui } \\
\text { Psicol }\end{array}$ & $\begin{array}{l}\text { Brasil } \\
2016\end{array}$ \\
\hline 4 & $\begin{array}{l}\text { Leal MC, Ayres } \\
\text { BVS, Pereira } \\
\text { APE, Sánchez AR, } \\
\text { Larouzé B }{ }^{(3)}\end{array}$ & $\begin{array}{l}\text { Nascer na prisão: gestação e parto atrás } \\
\text { das grades no Brasil }\end{array}$ & $\begin{array}{l}\text { Ciênc Saúde } \\
\text { Coletiva }\end{array}$ & $\begin{array}{l}\text { Brasil } \\
2016\end{array}$ \\
\hline 5 & $\begin{array}{l}\text { Ventura M, Simas } \\
\mathrm{L}, \text { Larouzé } \mathrm{B}^{(4)}\end{array}$ & $\begin{array}{l}\text { Maternidade atrás das grades: em busca } \\
\text { da cidadania e saúde. Um estudo sobre } \\
\text { a legislação brasileira }\end{array}$ & $\begin{array}{l}\text { Cad Saúde } \\
\text { Pública }\end{array}$ & $\begin{array}{l}\text { Brasil } \\
2015\end{array}$ \\
\hline 6 & $\begin{array}{l}\text { França AMB, } \\
\text { Silva JMO }\end{array}$ & Maternidade em situação de prisão & $\begin{array}{l}\text { Rev baiana } \\
\text { enferm }\end{array}$ & $\begin{array}{l}\text { Brasil } \\
2015\end{array}$ \\
\hline 7 & Mares S, Zwi K ${ }^{(19)}$ & $\begin{array}{l}\text { Sadness and fear: The experiences of } \\
\text { children and families in remote Australian } \\
\text { immigration detention }\end{array}$ & $\begin{array}{l}\text { J Paediatr Child } \\
\text { Health }\end{array}$ & $\begin{array}{l}\text { Austrália } \\
2015\end{array}$ \\
\hline 8 & Turney $\mathrm{K}^{(20)}$ & $\begin{array}{l}\text { Stress proliferation across generations? } \\
\text { Examining the relationship between } \\
\text { parental incarceration and childhood } \\
\text { health }\end{array}$ & $\begin{array}{l}\text { J Health Soc } \\
\text { Behav }\end{array}$ & $\begin{array}{l}\text { EUA } \\
2014\end{array}$ \\
\hline 9 & $\begin{array}{l}\text { Goshin LS, Byrne } \\
\text { MW, Henninger, } \\
\mathrm{AM}^{(5)}\end{array}$ & $\begin{array}{l}\text { Recidivism after release from a prison } \\
\text { nursery program }\end{array}$ & $\begin{array}{l}\text { Public Health } \\
\text { Nurs }\end{array}$ & $\begin{array}{l}\text { EUA } \\
2013\end{array}$ \\
\hline 10 & Sutherland $\mathrm{MA}^{(21)}$ & $\begin{array}{l}\text { Incarceration during pregnancy: } \\
\text { implications for women, newborns and } \\
\text { health care providers }\end{array}$ & $\begin{array}{l}\text { Nurs Womens } \\
\text { Health }\end{array}$ & $\begin{array}{l}\text { EUA } \\
2013\end{array}$ \\
\hline 11 & Haroche $\mathrm{F}^{(6)}$ & $\begin{array}{l}\text { Ameliorer la situation des méres et des } \\
\text { enfants en prision }\end{array}$ & $\begin{array}{l}\text { Soins Pediatr } \\
\text { Pueric }\end{array}$ & $\begin{array}{l}\text { França } \\
2013\end{array}$ \\
\hline 12 & $\begin{array}{l}\text { Goshin LS, Byrne } \\
\text { MW, Henninger } \\
\operatorname{AM}^{(7)}\end{array}$ & $\begin{array}{l}\text { Predictors of post-release research } \\
\text { retention and subsequent reenrollment for } \\
\text { women recruited while incarcerated }\end{array}$ & Res Nurs Health & $\begin{array}{l}\text { EUA } \\
2012\end{array}$ \\
\hline 13 & $\begin{array}{l}\text { Huang K, Atlas R, } \\
\text { Parvez } \mathrm{F}^{(22)}\end{array}$ & $\begin{array}{l}\text { The significance of breastfeeding to } \\
\text { incarcerated pregnant women: an } \\
\text { exploratory study }\end{array}$ & Birth & $\begin{array}{l}\text { EUA } \\
2012\end{array}$ \\
\hline
\end{tabular}

Fonte: Elaboração própria.

\section{Discussão}

Emergiram três categorias para propiciar melhor compreensão do material analisado, assim denominadas: vivenciando a gestação no cárcere, formação de vínculo afetivo mãe e filho no cárcere e sofrimento psíquico da separação do binômio.

\section{Vivenciando a gestação no cárcere}

A construção das penitenciárias femininas no Brasil foi baseada no preso masculino e não contempla as especificidades da mulher, em especial a mulher grávida ${ }^{23}$. O encarceramento feminino traz consigo a possibilidade de vivenciar o ciclo gravídico puerperal dentro da prisão, quer se 
trate da mulher presa grávida, quer da que engravida durante o tempo de seu encarceramento.

Historicamente, a prisão é vista como um ambiente perigoso, de desamparo, privação de liberdade, marcado pela precariedade, superlotação, más condições de higiene, celas pequenas e pelo desrespeito aos direitos individuais dos $\operatorname{presos}^{(3,9)}$.

Achados da pesquisa realizada em um presídio em Alagoas revelaram que o ambiente prisional, devido a sua heterogeneidade, oferece riscos de natureza física e psíquica, acrescidos, sobretudo, de transmissão de doenças infecto-contagiosas, aumentando assim a vulnerabilidade das mães e de seus filhos ${ }^{(17,18)}$.

Evidências científicas apontam que o impacto da adversidade durante a gestação, incluindo a exposição à violência, trauma e solidão, pode interferir no desenvolvimento normal da criança e afeta a saúde e o bem-estar da criança ao longo de sua vida ${ }^{(19)}$.

Estudo longitudinal realizado nos EUA, utilizando dados da Pesquisa Nacional de Saúde da Criança 2011-2012, estimou a relação entre o encarceramento dos pais e a saúde da criança em geral, além de uma variedade de condições de saúde física e mental, limitações de atividades e absenteísmo escolar e demonstrou que as crianças de pais encarcerados constituem uma população vulnerável e sofrem o impacto do estresse do encarceramento nas suas vidas ${ }^{(20)}$.

Outra pesquisa realizada por enfermeiras norte-americanas, que trabalhavam em unidades de parto e pós-parto e em instituições correcionais, sobre o encarceramento durante a gravidez e as implicações para as mulheres e os recém-nascidos, demonstrou que as mulheres grávidas encarceradas eram particularmente vulneráveis devido ao próprio ambiente da prisão e à redução do seu acesso aos serviços de saúde, evidenciados pela baixa cobertura de pré-natal, à dificuldade para realizar os exames durante a gestação e aos poucos cuidados fornecidos durante o parto e o pós-parto ${ }^{(21)}$.

A gestação e o nascimento constituem eventos sociais que marcam momentos importantes na vida da mulher e da criança. É uma experiência singular e permeada de especificidades. Desde o início da gravidez, a emoção que a mãe vivencia no estado gravídico transmite para o feto. Portanto, a gestação vivida em um contexto adverso, tal como o cárcere, traz repercussões significativas tanto para vida da mulher quanto para sua criança.

\section{Formação de vínculo afetivo mãe e filho no} cárcere

O vínculo construído pela gestante com o bebê, durante o processo da gestação vem sendo considerado um importante indicador da qualidade da relação que o binômio estabelecerá nos primeiros meses de vida. Alguns fatores podem interferir nessa relação mãe-filho e terá implicações diretas para o estabelecimento desses vínculos, dentre eles a situação de encarceramento materno.

Estudo sobre as particularidades do binômio atrás das grades revelou que o vínculo mãe-filho dentro do cárcere é intrigante, devido às inconformidades do espaço prisional. Este interfere no desenvolvimento biopsicossocial das crianças, devido ao próprio ambiente fechado da cela, as regras do sistema prisional, as péssimas condições de higiene, o conglomerado de pessoas, a facilidade de propagação de doenças infecto-contagiosa e a fragilidade das redes de apoio ${ }^{(16)}$.

O início da vinculação afetiva está muito relacionado à experiência do parto e aos primeiros encontros entre mãe-filho. Assim, proporcionar o contato imediato desse binômio, logo após o parto, é fundamental para a criação do vínculo. Pesquisa realizada sobre a percepção das mulheres em situação de privação de liberdade destaca que as mães presas evidenciam que o encarceramento enfraquece o vínculo entre mães e filhos e compromete a relação de cuidado ${ }^{(9)}$.

A criança precisa sentir-se cuidada para estabelecer, entre ela e a figura do apego, a chamada base de segurança, a qual vai proporcionar-lhe uma estrutura que influenciará toda a sua vida. Por isso, é fundamental que, mesmo num contexto de prisão, exista um ambiente para a mãe vivenciar a formação dos laços com seu filho. 
Estudo exploratório sobre o significado da amamentação para mulheres grávidas encarceradas revelou que a vivência da amamentação foi o principal fator para estabelecer uma relação estreita com seu bebê. Quase todas as mulheres entrevistadas acreditavam que a amamentação era uma forma importante e natural de se relacionar com seus filhos, e afirmaram que "amamentar é ligar". A amamentação contribuiu, assim, para fortalecer a identidade materna e para que essa mulher desenvolvesse seu papel materno de proteção, provisão e ligação com seu bebêt $\hat{e}^{(22)}$.

A permanência do recém-nascido/lactente junto à mãe torna-se, de fato, importante não só para a criança, mas para ambas, pois essa presença amortece o choque e suaviza a pena, fazendo com que as próprias mães não sintam a solidão, o que pode tornar a vivência do cárcere menos pesada ${ }^{(16)}$.

Portanto, no que tange às particularidades do vínculo entre mães e filhos, independentemente do local em que se encontra o binômio, ela é marcante. Mesmo num ambiente carcerário, é relevante a presença materna, com seu calor e seu vínculo, para que a criança estabeleça uma relação saudável consigo mesma e com outras pessoas, pois essas mães em privação de liberdade demonstram, de forma incondicional, amor e cuidado por seus filhos.

Por fim, é nos primeiros meses de convivência entre mãe e filho que se desenvolve a percepção sobre a maternidade e surge a necessidade da vinculação. No momento que a criança começa a se autorregular, a mãe representa segurança e limite no processo de desenvolvimento, tendo um papel fundamental na vida dessa criança ${ }^{(9)}$.

\section{Sofrimento psíquico na separação do binômio}

O processo de separação entre mãe e filho caracteriza a maternidade como dolorosa e gera sentimentos de perda e de impotência. Para as mães que participaram da pesquisa num presídio feminino no norte do Rio Grande do Sul, o afastamento decorrente do encarceramento enfraqueceu o vínculo entre mãe e filho e comprometeu a relação de cuidado ${ }^{(9)}$.

O cárcere, por si só, promove danos emocionais e gera ansiedade que traz sofrimento inerente à privação da liberdade ${ }^{(18)}$. Quando a maternidade é vivenciada nesse contexto, outro fator surge, que é a separação que ocorrerá entre mãe e filho.

Nos EUA existem diversos programas para que as mulheres encarceradas elegíveis possam cuidar de seus filhos durante a amamentação até aproximadamente 18 meses. Entretanto, a política mais prevalente no país é separar a criança de sua mãe nas primeiras 48 horas após o parto ${ }^{(7)}$.

No Brasil, segundo a Lei de Execução Penal e a Lei n. 11.942/2009, a mulher tem direito de permanecer com seu filho até 6 meses. Depois desse tempo, ele é separado da mãe ${ }^{(10)}$. Essa criança, após a separação da sua mãe, pode ser encaminhada, conforme ordem judicial, para algum familiar (primeiramente o pai, se estiver em liberdade, as avós ou os tios). Em caso de impossibilidade da família e nas unidades penitenciárias que possuem creche, essas crianças são encaminhadas para as creches (ficando lá até os 7 anos). A terceira possibilidade é o encaminhamento da criança para instituições denominadas abrigos.

Estudos psiquiátricos salientam que a separação entre mãe e filho pode desenvolver problemas no pleno desenvolvimento da saúde mental das crianças nos primeiros anos de vida. Esta descontinuidade de apego e afetividade nos primeiros anos de vida pode acarretar problemas futuros de desordem de caráter, neurose e psicopatia. Portanto, a separação precoce entre mãe e filho exerce forte influência no desenvolvimento da personalidade da criança ${ }^{(16)}$.

Pesquisas longitudinais na mais antiga prisão norte-americana apontam que as crianças que vivenciaram o berçário com suas mães e foram amamentadas e desfrutaram de mais tempo junto com sua genitora tiveram melhores resultados com relação a problemas relacionados ao desenvolvimento infantil quando comparadas a crianças que foram separadas precocemente de suas mães. Estas apresentaram maiores 
transtornos de comportamentos, distúrbios de ansiedade e estresse pós-traumático com fortes repercussões na saúde mental ${ }^{(5)}$.

A atuação da enfermeira no cuidado a essa criança e a sua mãe em privação de liberdade é de fundamental importância, haja vista que a Política Nacional de Atenção Integral à Saúde das Pessoas Privadas de Liberdade no Sistema Prisional (PNAISP) assegura a inclusão da população carcerária no Sistema Único de Saúde (SUS).

Dentre as limitações deste estudo, destaca-se o reduzido número de artigos encontrados que avaliassem o seguimento das crianças após a sua saída do cárcere e as repercussões física e psíquica no desenvolvimento infantil.

\section{Conclusão}

O estudo mostrou o impacto do ambiente do cárcere para a formação da relação mãe-filho e para a construção do vínculo entre eles, fator imprescindível para a saúde física e mental das crianças, com forte impacto no seu desenvolvimento.

Constatou-se um número reduzido de artigos científicos que abordassem essa temática, evidenciando a necessidade de se ampliarem as pesquisas nessa área, com enfoque nos estudos de acompanhamento das crianças que saem dos presídios brasileiros. As publicações concentraram-se nos anos de 2015 e 2016, evidenciando a urgência de estudos sobre o desdobramento do cárcere no desenvolvimento físico e psíquico dessas crianças, visto que a grande parte delas, quando sai do contexto do cárcere, continua vivendo em situação de extrema vulnerabilidade social.

Conclui-se que é necessária maior atenção à mulher que vivencia a maternidade em situação de privação de liberdade, pois o ambiente da prisão tem fortes implicações para o estabelecimento da relação mãe-filho e para a formação do vínculo nesse binômio.

Essas reflexões apontam a necessidades de conceder a essas mães e crianças que vivenciam a invisibilidade social, jurídica e administrativa os direitos já assegurados pela Constituição, pois a díade mãe-filho está exposta a situação de vulnerabilidade com repercussões em todo o processo biopsicológico da criança e da mãe, que serão prejudicados nesse contexto de cárcere e deverão ser atendidos, a fim minimizar as complicações.

\section{Colaborações:}

1. concepção, projeto, análise e interpretação dos dados: Denise Santana Silva dos Santos;

2. redação do artigo, revisão crítica relevante do conteúdo intelectual: Denise Santana Silva dos Santos;

3. aprovação final da versão a ser publicada: Tânia Christiane Ferreira Bispo.

\section{Referências}

1. Amaral MF, Bispo TCF. Mães e filhos atrás das grades: um olhar sobre o drama do cuidar de filhos na prisão. Rev Enferm Contemporânea. 2016 jan/jul;5(1):51-8.

2. Bispo TCF, Nunes FN, Sacramento RALA, Rebouças LT, Santos SM. Percepções das gestantes e puérperas presidiárias acerca do contexto carcerário. Rev Enferm Contemporânea. 2016 jan/ jul;5(1):43-50.

3. Leal MC, Ayres BVS, Pereira APE, Sánchez AR, Larouzé B. Nascer na prisão: gestação e parto atrás das grades no Brasil. Ciênc Saúde Coletiva [Internet]. 2016 [cited 2017 Fev 10];21(7):206170. Available from: http://www.scielo.br/pdf/csc/ v21n7/1413-8123-csc-21-07-2061.pdf

4. Ventura M, Simas L, Larouzé B. Maternidade atrás das grades: em busca da cidadania e da saúde. Um estudo sobre a legislação brasileira. Cad Saúde Pública. 2015 mar;31(3):607-19.

5. Goshin LS, Byrne MW, Henninger AM. Recidivism after release from a prison nursery program. Public Health Nurs. 2013 Mar-Apr;31(2):109-17.

6. Haroche F. Ameliorer la situation des méres et des enfants en prision. Soins Pediatr Pueric. 2013;32(5):215-22.

7. Goshin LS, Byrne MW, Henninger AM. Predictors of post-release research retention and subsequent reenrollment for women recruited 
while incarcerated. Res Nurs Health. 2012 Feb;35(1):94-104.

8. Brasil. Ministério da Justiça. Departamento Penitenciário Nacional. Levantamento nacional de informações penitenciarias Infopen mulheres. [Internet]. Brasília; 2014 [cited 2017 Feb 10]. Available from: http://www.justica.gov.br/noticias/ estudo-traca-perfil-da-populacao-penitenciariafeminina-no-brasil/relatorio-infopen-mulheres.pdf

9. Soares IR, Cenci CMB, Oliveira LRF. Mães no cárcere: percepção de vínculo com os filhos. Estud Pesqui Psicol. 2016 jan-abr;16 (1):27-45.

10. Brasil. Lei n. 11.942, de 28 de maio de 2009. Dá nova redação aos arts. 14, 83 e 89 da Lei n. 7.210, de 11 de julho de 1984 - Lei de Execução Penal, para assegurar às mães presas e aos recém-nascidos condições mínimas de assistência. Brasília; 2009. Diário Oficial [da] República Federativa do Brasil, Brasília, DF, 22 maio 2009. Seção 1, p.1.

11. Brasil. Ministério da Justiça. Diretoria de Políticas Penitenciárias. Departamento Penitenciário Nacional. Mulheres Presas - Dados Gerais. Projeto Mulheres/ DEPEN. Brasília, 2011.

12. Brasil. Ministério da Justiça. Conselho Nacional de Política Criminal e Penitenciária. Resolução n. 4, de 15 de julho de 2009. Brasília; 2009.

13. Shehadeh A, Loots G, Vanderfaeillie J, Derluyn I. The impact $f$ parental on the psychological wellbeing of Palestinian children. PLOS ONE [Internet]. 2015 [cited 2017 Feb 22];10(7):e0133347. Available from: http://journals.plos.org/plosone/ article?id=10.1371/journal. pone. 0133347

14. Marconi MA, Lakatos EM. Técnicas de pesquisa. 6a ed. São Paulo: Atlas; 2011.

15. Bardin L. Análise de conteúdo. 5a ed. Lisboa, PT: Edições 70; 2011.
16. Matão MEL, Miranda DB, Malaquias A, Souza EL. Maternidade atrás das grades: particularidades do binômio mãe-filho. Rev Enferm Centro-Oeste Min. 2016 maio;6(2):2235-46.

17. França AMB, Silva JMO. A mulher em situação de prisão e a vivência da maternidade. Rev enferm UFPE on line. 2016 maio [cited 2017 Jan 15];10(5):1891-4. Available from: https:// portalseer.ufba.br/index.php/enfermagem/article/ view/14026/pdf_22

18. França AMB, Silva JMO. Maternidade em situação de prisão. Rev baiana enferm. 2015 out/ dez;29(4):411-20.

19. Mares S, Zwi K. Sadness and fear: The experiences of children and families in remote Australian immigration detention. J Paediatr Child Health. $2015 \mathrm{Jul} ; 51(7): 663-9$.

20. Turney K. Stress proliferation across generations? Examining the relationship between parental incarceration and childhood health. J Health Soc Behay. 2014 Sept;55(3):302-19.

21. Sutherland MA. Incarceration during pregnancy: implications for women, newborns and health care providers. Nurs Womens Health. 2013 June-July;17(3):225-30.

22. Huang K, Atlas R, Parvez F. The significance of breastfeeding to incarcerated pregnant women: an exploratory study. Birth. 2012 Jun;39(2):145-55.

23. Cerneka HA. Homens que menstruam: considerações acerca do sistema prisional às especificidades da mulher. Veredas Direito. 2009 jan-jun;6(11):61-78.

Recebido: 29 de abril de 2017 Aprovado: 27 de fevereiro de 2018 Publicado: 23 de maio de 2018

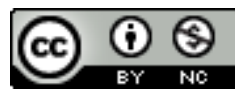

A Revista Baiana de Enfermagem utiliza a Licença Creative Commons - Atribuição-NãoComercial 4.0 Internacional. https://creativecommons.org/licenses/by-nc/4.0/ Este artigo é de acesso aberto distribuído sob os termos da Licença Creative Commons (CC BY-NC).

Esta licença permite que outros remixem, adaptem e criem a partir do seu trabalho para fins não comerciais e, embora, os novos trabalhos tenham de lhe atribuir o devido crédito e não possam ser usados para fins comerciais, os usuários não têm de licenciar esses trabalhos derivados sob os mesmos termos. 